\title{
Infrasound/seismic observation of the Hayabusa reentry: Observations and preliminary results
}

\author{
Yoshiaki Ishihara $^{1 *}$, Yoshihiro Hiramatsu ${ }^{2}$, Masa-yuki Yamamoto ${ }^{3}$, Muneyoshi Furumoto ${ }^{4}$, and Kazuhisa Fujita ${ }^{5}$ \\ ${ }^{1}$ RISE Project, National Astronomical Observatory of Japan, 2-12 Hoshigaoka, Mizusawa, Oshu, Iwate 023-0861, Japan \\ ${ }^{2}$ School of Natural System, College of Science and Engineering, Kanazawa University, Kakuma, Kanazawa, Ishikawa 920-1192, Japan \\ ${ }^{3}$ School of Systems Engineering, Kochi University of Technology, 185 Miyanokuchi, Tosayamada, Kami, Kochi 782-8502, Japan \\ ${ }^{4}$ Graduate School of Environmental Studies, Nagoya University, Furo, Chikusa, Nagoya, Aichi 464-8602, Japan \\ ${ }^{5}$ Aerospace Research and Development Directorate, Japan Aerospace Exploration Agency, \\ 7-44-1 Jindaijihigashi, Chofu, Tokyo 182-8522, Japan
}

(Received July 25, 2011; Revised January 13, 2012; Accepted January 19, 2012; Online published August 16, 2012)

\begin{abstract}
The Hayabusa, the world's first sample-return minor body explorer, returned to the Earth, and reentered the Earth's atmosphere on June 13, 2010. Multi-site ground observations of the Hayabusa reentry were carried out in the Woomera Prohibited Area (WPA), Australia. The ground observations were configured with optical imaging with still and video recordings, spectroscopies, and shockwave detection with infrasound and seismic sensors. At three main stations, we installed small aperture infrasound/seismic arrays, as well as three single component seismic sub stations. The infrasound and seismic sensors clearly recorded sonic-boom-type shockwaves from the Hayabusa Sample Return Capsule (H-SRC) and the disrupted fragments of the Hayabusa Spacecraft $(\mathrm{H}-\mathrm{S} / \mathrm{C})$ itself. Positive overpressure values of shockwaves (corresponding to the H-SRC) recorded at the three main stations were $1.3 \mathrm{~Pa}, 1.0 \mathrm{~Pa}$, and $0.7 \mathrm{~Pa}$ with slant distances of $36.9 \mathrm{~km}, 54.9 \mathrm{~km}$, and $67.8 \mathrm{~km}$, respectively. Incident vectors of the shockwave from the $\mathrm{H}$-SRC at all three arrays are estimated by an F-K spectrum and agree well with those predicted. Particle motions of ground motions excited by the shockwave show characteristics of a typical Rayleigh wave.
\end{abstract}

Key words: Artificial meteorite fall, Hayabusa reentry, meteor shockwave, infrasound-seismic observation.

\section{Introduction}

After 7 years and a 6-billion-km challenging journey in the solar system, the Hayabusa (formerly called MUSESC; the first sample-return explorer to a Near Earth Asteroid) returned to Earth on June 13, 2010. Following the reentries of the Genesis in 2004 (ReVelle et al., 2005; Jenniskens et al., 2006) and the Stardust in 2006 (Edwards et al., 2007), the return of the Hayabusa Sample Return Capsule (H-SRC) was the third direct reentry event from the interplanetary transfer orbit to the Earth at a velocity of over $11.2 \mathrm{~km} / \mathrm{s}$. In addition, it was the world's first case of a direct reentry of the spacecraft $(\mathrm{H}-\mathrm{S} / \mathrm{C})$ itself from the interplanetary transfer orbit.

With respect to the nominal trajectory of the H-SRC reentry, four optical stations were set both inside and near the Woomera Prohibited Area (WPA), Australia, targeting on peak-heat and/or front-heat temperature profiles of the ablating thermal protection system for studying engineering aspects. In addition, the $\mathrm{H}-\mathrm{SRC}$ and the $\mathrm{H}-\mathrm{S} / \mathrm{C}$ reentries

*Now at Environmental Information Analysis Section, Center for Environmental Measurement and Analysis, National Institute for Environmental Studies, 16-2 Onogawa, Tsukuba, Ibaraki 305-8506, Japan.

Copyright (c) The Society of Geomagnetism and Earth, Planetary and Space Sciences (SGEPSS); The Seismological Society of Japan; The Volcanological Society of Japan; The Geodetic Society of Japan; The Japanese Society for Planetary Sciences; TERRAPUB.

doi:10.5047/eps.2012.01.003 provide very good analogues for studying bolide-size meteors and meteorite falls. Thus, we carried out a groundbased observations to study various aspects of meteor science (Fujita et al., 2011).

In order to understand bolide, and meteorite, falls, observations of such events from the ground are now routinely made in many regions on the Earth using various methods such as still-photographs (e.g., Halliday et al., 1981, 1996), video recording (e.g., Borovičkia et al., 2003), and spectroscopy measurements (e.g., Kasuga et al., 2005). The purpose of these observations are the optical detection and analysis of light emitted by bolides. A meteoroid, or a bolide, with a supersonic velocity generates shockwaves in the atmosphere. Therefore, not only the optical observations mentioned above, but also the infrasound monitoring of shockwaves (e.g., McIntosh et al., 1976) and the seismic monitoring of shockwaves that convert to ground motions (e.g., Nagasawa, 1978; Cevolani, 1994; Brown et al., 2002; Ishihara et al., 2003, 2004; Pujol et al., 2006) have also been carried out. From this point of view, we deployed specific instruments such as infrasound sensors, seismic sensors, and an audio recorder as well as common optical instruments.

At 13:51:12 UT on June 13, 2010, the reentry of the HSRC and the H-S/C in the Earth's atmosphere successfully took place on an exact schedule and trajectory, and provided fruitful images and signals on almost all cameras and infrasound/seismic sensors. Moreover, several audible sound 


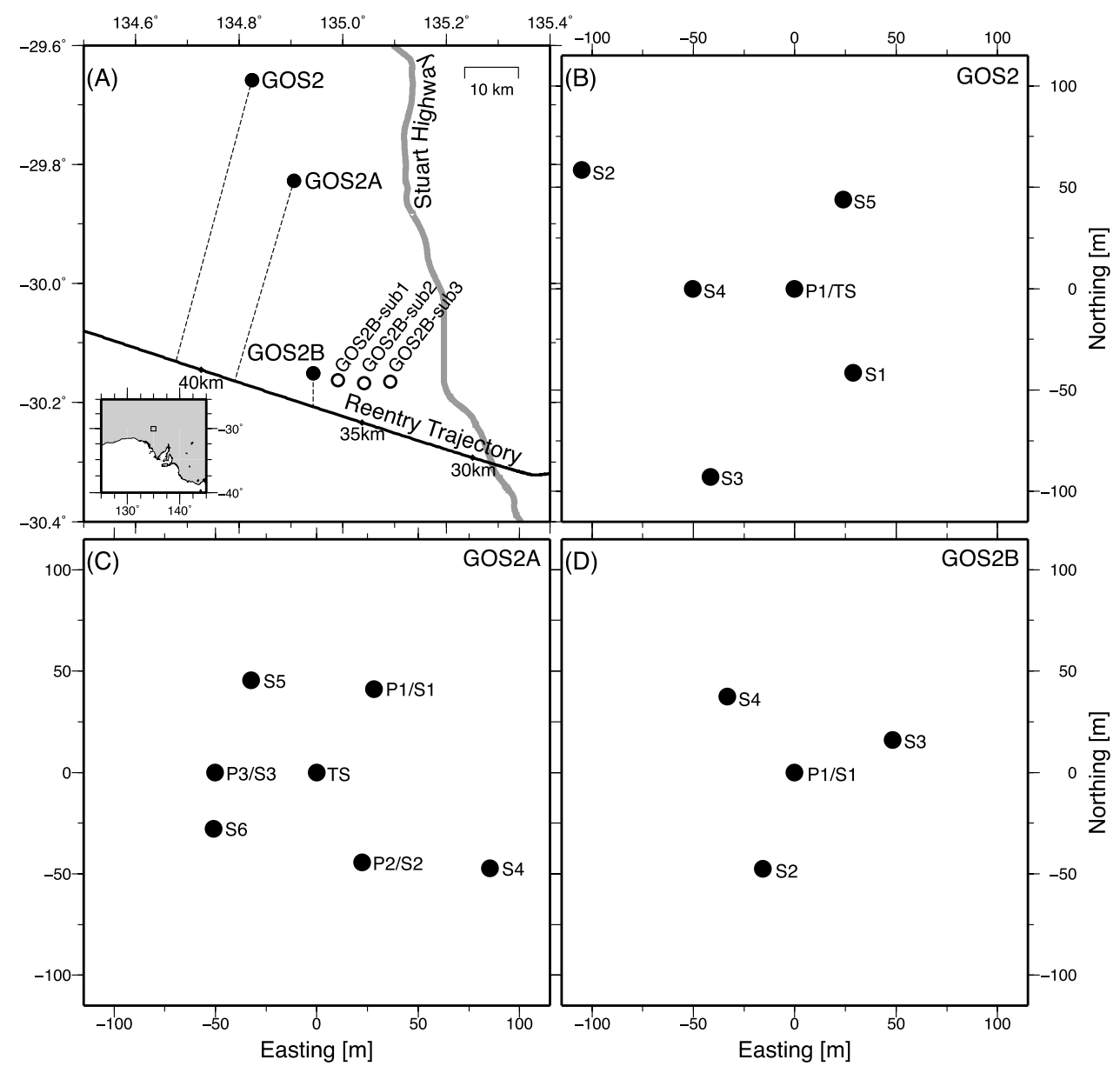

Fig. 1. Location map of infrasound and seismic observation stations in WPA (A) and the geometry of three infrasound/seismic arrays (B) (C) (D). Letters indicate instruments types as follows, P: infrasound sensor, S: seismic sensor (vertical component only), and TS: seismic sensor (three component).

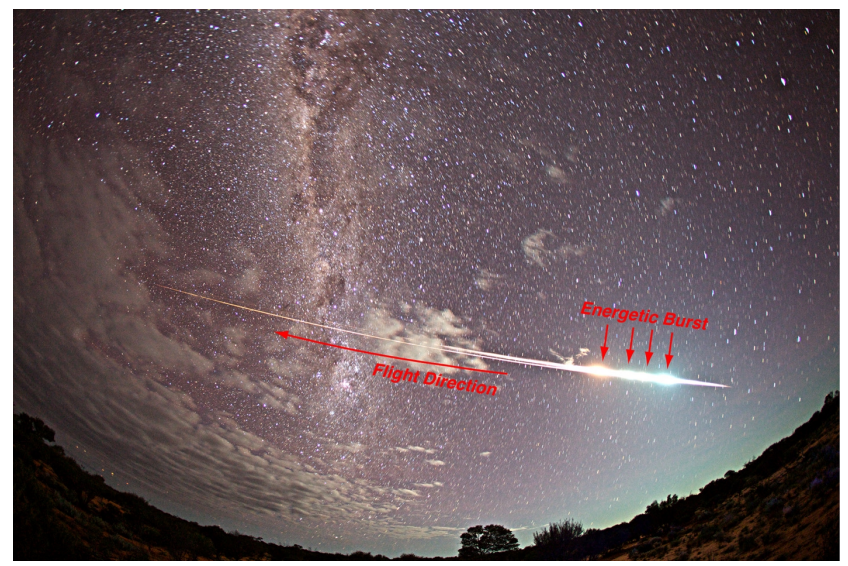

Fig. 2. A long exposure photograph of the Hayabusa reentry fireball. Canon EOS 5D mark II with $15 \mathrm{~mm}$ diagonal fisheye, F/2.8, ISO = 3200, and a 120-s exposure.

signals were detected at one of the observation sites about $70 \mathrm{~km}$ from the trajectory. In this paper, we report details of the infrasound/seismic observations and some preliminary results.

\section{Infrasound and Seismic Observations}

For the infrasound observation, we used condensermicrophone-type sensors. Eight porous garden soaker tubes 3-m long were attached to each infrasound sensor to reduce wind noise by a spatial filtering effect. A record of the infrasound sensor was digitized at a frequency of $100 \mathrm{~Hz}$. For the seismic observations, we used three-component velocitytype seismic sensors and vertical velocity-type seismic sensors. A record of each three-component sensor was digitized at a frequency of $100 \mathrm{~Hz}$, and a record of each vertical sensor was digitized at a frequency of $125 \mathrm{~Hz}$. Time stamps were accurately maintained with an accuracy better than $1 \mathrm{~ms}$, using GPS time. 
Table 1. Locations and array geometries of infrasound/seismic stations.

\begin{tabular}{|c|c|c|c|c|}
\hline \multicolumn{2}{|c|}{ GOS2 $\left(134.82463^{\circ},-29.65829^{\circ}, 153.0 \mathrm{~m}\right)$} & \multirow[b]{2}{*}{ Easting $(\mathrm{m})$} & \multirow[b]{2}{*}{ Northing (m) } & \multirow[b]{2}{*}{ Height (m) } \\
\hline Element name & Instrument & & & \\
\hline P1 & Chaparral Physics Model-2 & 0 & 0 & 0 \\
\hline TS & Sercel (Mark Products) L-28-3D & 0 & 0 & 0 \\
\hline $\mathrm{S} 1$ & Hakusan Corp. SG820 & 28.799 & -41.393 & 0.091 \\
\hline $\mathrm{S} 2$ & Hakusan Corp. SG820 & -104.935 & 58.519 & 2.142 \\
\hline $\mathrm{S} 3$ & Hakusan Corp. SG820 & -41.502 & -92.750 & -0.295 \\
\hline $\mathrm{S} 4$ & Hakusan Corp. SG820 & -50.176 & -0.006 & 0.527 \\
\hline S5 & Hakusan Corp. SG820 & 24.066 & 43.929 & 0.448 \\
\hline \multicolumn{2}{|c|}{ GOS2A $\left(134.90616^{\circ},-29.82752^{\circ}, 156.0 \mathrm{~m}\right)$} & & & \\
\hline Element name & Instrument & Easting $(\mathrm{m})$ & Northing (m) & Height (m) \\
\hline P1 & Chaparral Physics Model-25 & 28.141 & 41.129 & 0.061 \\
\hline $\mathrm{P} 2$ & Chaparral Physics Model-25 & 22.407 & -44.314 & -0.119 \\
\hline P3 & Chaparral Physics Model-25 & -50.209 & 0.034 & 0.047 \\
\hline TS & Sercel (Mark Products) L-28-3D & 0 & 0 & 0 \\
\hline $\mathrm{S} 1$ & Hakusan Corp. SG820 & 28.141 & 41.129 & 0.061 \\
\hline $\mathrm{S} 2$ & Hakusan Corp. SG820 & 22.407 & -44.314 & -0.119 \\
\hline $\mathrm{S} 3$ & Hakusan Corp. SG820 & -50.209 & 0.034 & 0.047 \\
\hline S4 & Hakusan Corp. SG820 & 85.427 & -47.226 & 0.026 \\
\hline S5 & Hakusan Corp. SG820 & -32.425 & 45.386 & 0.523 \\
\hline S6 & Hakusan Corp. SG820 & -51.057 & -27.886 & 0.047 \\
\hline \multicolumn{2}{|c|}{ GOS2B $\left(134.94308^{\circ},-30.15124^{\circ}, 158.0 \mathrm{~m}\right)$} & & & \\
\hline Element name & Instrument & Easting (m) & Northing (m) & Height $(\mathrm{m})$ \\
\hline P1 & Chaparral Physics Model-2 & 0 & 0 & 0 \\
\hline S1 & Hakusan Corp. SG820 & 0 & 0 & 0 \\
\hline $\mathrm{S} 2$ & Hakusan Corp. SG820 & -15.706 & -47.636 & 0.255 \\
\hline $\mathrm{S} 3$ & Hakusan Corp. SG820 & 48.309 & 15.885 & -0.494 \\
\hline $\mathrm{S} 4$ & Hakusan Corp. SG820 & -33.292 & 37.454 & 0.340 \\
\hline \multicolumn{2}{|c|}{ GOS2B-sub1 $\left(134.99007^{\circ},-30.16267^{\circ}, 168.0 \mathrm{~m}\right)$} & & & \\
\hline Element name & Instrument & Easting $(\mathrm{m})$ & Northing (m) & Height $(\mathrm{m})$ \\
\hline- & Hakusan Corp. SG820 & 0 & 0 & 0 \\
\hline \multicolumn{2}{|c|}{$\mathrm{GOS} \mathrm{B}-\mathrm{sub2}\left(135.04060^{\circ},-30.16781^{\circ}, 168.0 \mathrm{~m}\right)$} & & & \\
\hline Element name & Instrument & Easting (m) & Northing (m) & Height $(\mathrm{m})$ \\
\hline- & Hakusan Corp. SG820 & 0 & 0 & 0 \\
\hline \multicolumn{2}{|c|}{ GOS2B-sub3 $\left(135.09196^{\circ},-30.16503^{\circ}, 168.0 \mathrm{~m}\right)$} & & & \\
\hline Element name & Instrument & Easting (m) & Northing (m) & Height $(\mathrm{m})$ \\
\hline- & Hakusan Corp. SG820 & 0 & 0 & 0 \\
\hline
\end{tabular}

The infrasound and seismic sensors mentioned above were deployed as three arrayed infrasound/seismic (GOS2, GOS2A, and GOS2B), and as three single sensor seismic (GOS2B-sub1, GOS2B-sub2, and GOS2B-sub3), stations (Fig. 1; Table 1) to estimate the arrival directions of the sonic-boom-type shockwaves from the H-SRC and the fragments of the H-S/C, as well as the point-source-type shockwaves from the energetic disruptions of the $\mathrm{H}-\mathrm{S} / \mathrm{C}$, in order to investigate the precise parameters of the pressure waves. We determined the locations of the stations using a handheld GPS (Garmin, Oregon 450) and the array geometries using a total station (SOKKIA, SET530R). In addition, at the GOS2 station, we tried to detect shockwaves in the audible band using a small microphone with a digital voice recorder (OLYMPUS, Voice-Trek V-40).

\section{Results and Discussion}

At just after the reentry time, we observed the spectacular fireballs of the H-SRC and the fragments of the $\mathrm{H}$ -
S/C (Fig. 2). About 297 s after the reentry time, all observers at the GOS2 station heard multiple sounds like fardistant fireworks. The estimated shockwave arrival time at the GOS2 station, based on the nominal aerial trajectory with an isothermally-still atmosphere, is $301 \mathrm{~s}$ after the reentry time. The infrasound waveform at the GOS2 station (Fig. 3), simultaneously recorded with the audible sound, shows a clear N-wave shape. The shockwave generated by a hypersonic flying object is a compressional shockwave followed by a rarefactional shockwave. The compressional and rarefactional shockwaves cause rapid downward and upward ground motions, respectively. These successive ground motions are recorded as a shape of a reversed $\mathrm{N}$ on a seismogram. We therefore, conclude those sounds are due to sonic booms generated by the supersonic movement of the H-SRC and the multiple fragments of the H-S/C. Those sonic booms were successfully detected by infrasound and seismic sensors at all observation stations and the audible recording at the GOS2 station. Here, we focus on the main 


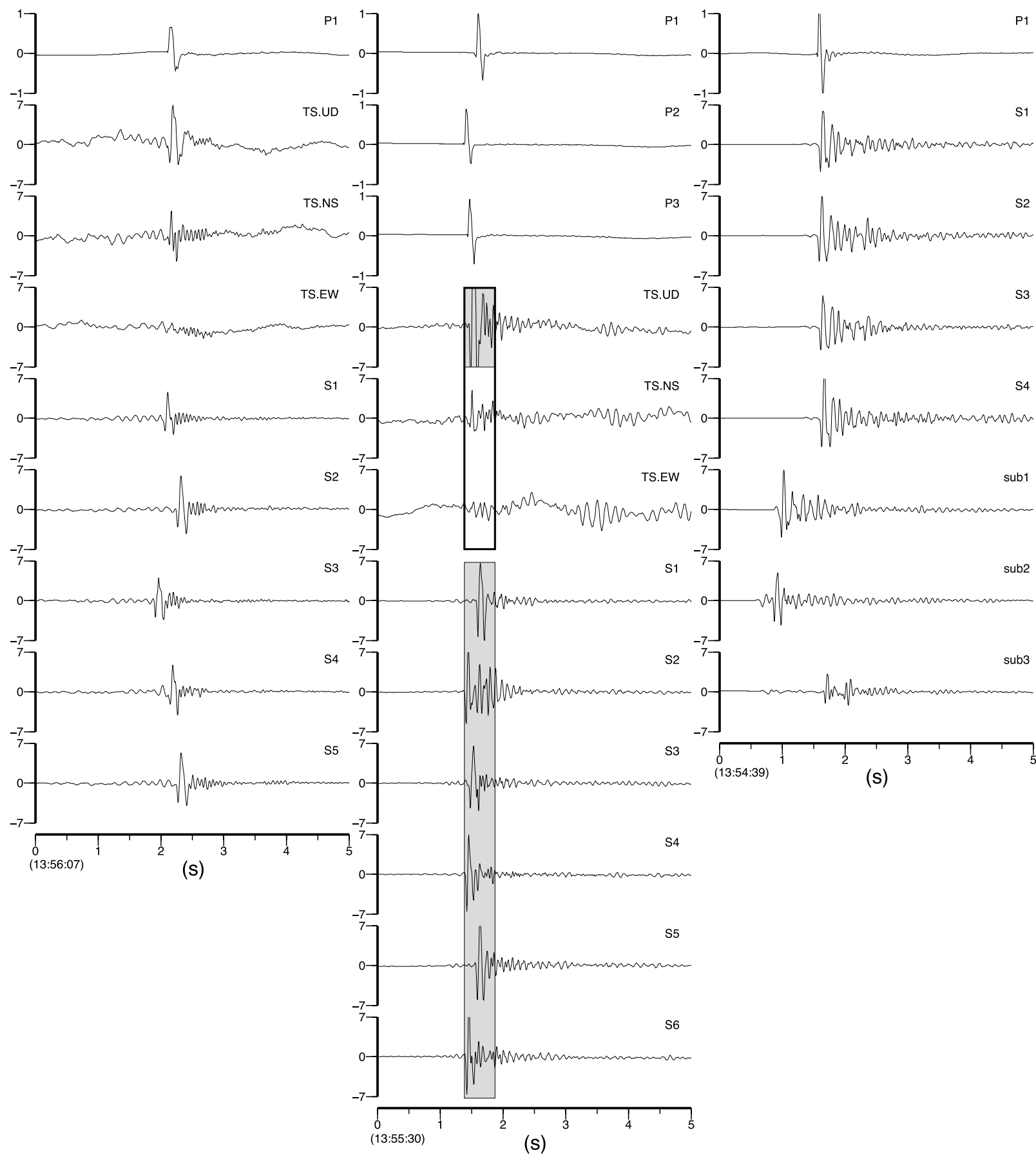

Fig. 3. Infrasound and seismic waveforms (displacement) recorded at GOS2, GOS2A, GOS2B, and GOS2B-sub1 to GOS2B-sub3 stations. Each trace is 5-s long. Dimension of amplitude is Pa for infrasound (P1, P2, and P3) and $10^{-8} \mathrm{~m}$ for ground motion (TS-UD, TS-NS, TS-EW, S1, S2, S3, S4, S5, S6, sub1, sub2, and sub3). Hatched parts of GOS2A are used for array analysis. Enclosed parts of GOS2A TS-UD, TS-NS, and TS-EW traces are used for particle-motion analysis.

sonic boom signal from the H-SRC. Details of the sonic booms from the fragments of $\mathrm{H}-\mathrm{S} / \mathrm{C}$ and the audible sound are reported in another paper (Yamamoto et al., 2011).

Figure 3 shows waveforms observed by the infrasound and seismic sensors at all stations. The seismic waveforms are converted to ground displacements by a time integral. Each infrasound signal indicates a characteristic of an $\mathrm{N}$ wave, while the seismic signals indicate inverse- $\mathrm{N}$ signatures, showing clearly that the observed signals are the sonic booms accompanying the reentry of Hayabusa. The amplitudes (positive overpressure) of the infrasound signals recorded at the GOS2, GOS2A, and GOS2B stations are about $0.7,1.0$, and $1.3 \mathrm{~Pa}$, respectively. These amplitudes are factors of 2-3 smaller than the theoretical predictions of equations (14) and (25) of ReVelle (1976). In our calculation, we estimate the shockwave source positions based on the nominal aerial trajectory with an isothermally-still atmosphere. The source height at each station are GOS2: $40.6 \mathrm{~km}$, GOS2A: $38.9 \mathrm{~km}$, and GOS2B: $36.5 \mathrm{~km}$ (i.e. slant ranges are GOS2: $67.8 \mathrm{~km}, \mathrm{GOS} 2 \mathrm{~A}: 54.9 \mathrm{~km}$, and GOS2B: $36.9 \mathrm{~km})$. These values of the source positions and the slant ranges must have some errors resulting from effects 


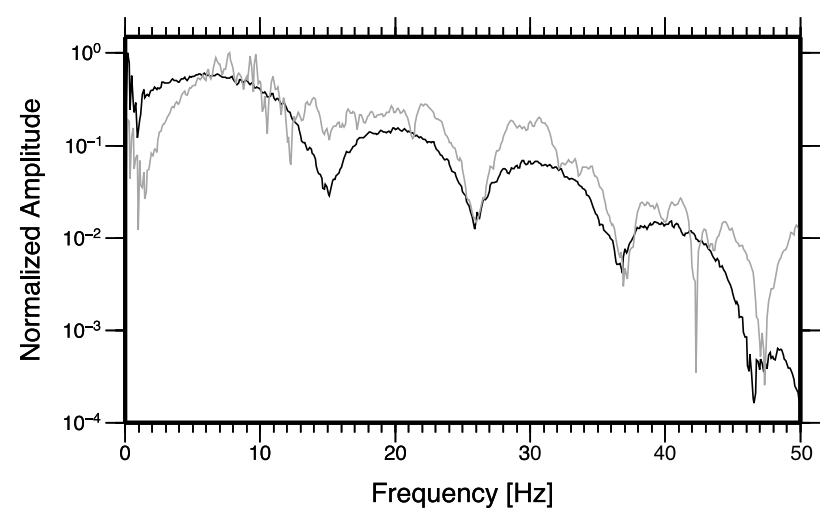

Fig. 4. Amplitude spectrum of infrasound (GOS2A-P3; black line) and ground displacement (GOS2A-S3; gray line) waveforms of shockwave (time window of 13:55:30.00 to 13:55:35.12).
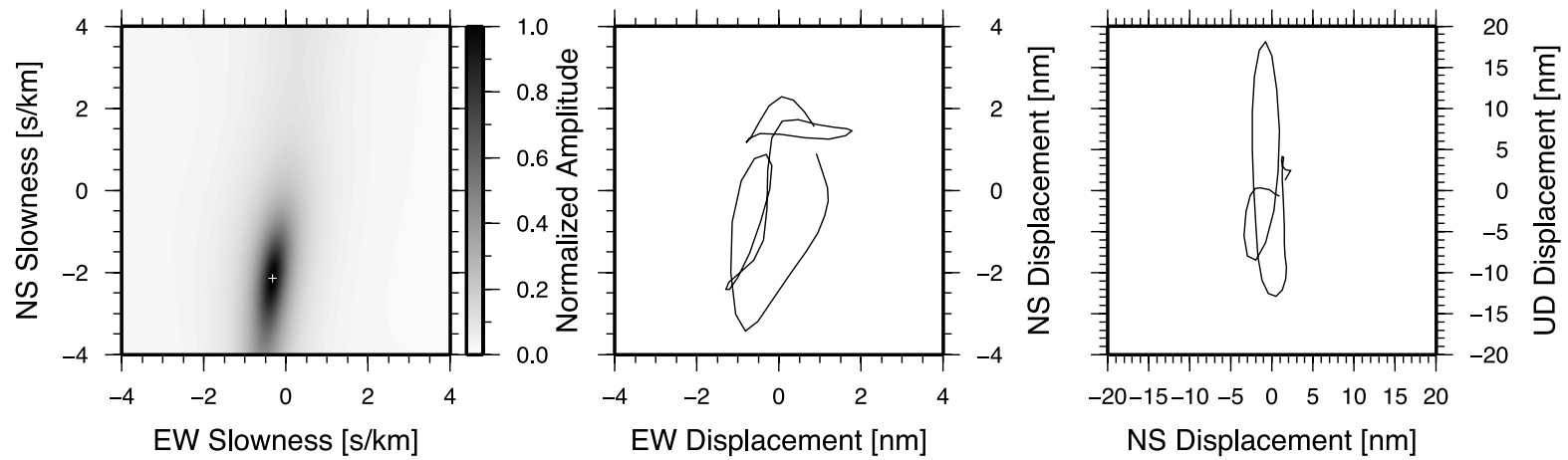

Fig. 5. F-K (MUSIC) spectrum and particle motion of ground motion ( $1-3 \mathrm{~Hz}$ band-pass filtered and a time window of $0.5 \mathrm{~s}$ shown by a gray hatch in Fig. 2) converted from shockwave at GOS2A infrasound/seismic array. The gray scale indicates a normalized amplitude and the white cross indicates the largest amplitude point (NS: $-2.13 \mathrm{~s} / \mathrm{km}, \mathrm{EW}:-0.32 \mathrm{~s} / \mathrm{km}$ ) of the F-K spectrum. For the MUSIC analysis, we used all the waveform data of the vertical component of all seismometers at the GOS2A station.

neglected in this study (e.g., winds). However, these effects only result in an error of the source position of up to $1 \mathrm{~km}$, and an error of the real propagating distances of up to a few kilometers. Such small errors do not explain the factor 2-3 discrepancy of the amplitudes mentioned above. This discrepancy is probably due to an incompleteness in the theoretical considerations. Especially, equation (14) of ReVelle (1976) proposed that the shockwave relaxation radius (the propagation distance of the shockwave decay from a strong shock, to a weak shock, regime) $R_{0}$ is almost equal to the product of a meteoroid diameter and it's Mach number. This relation is derived empirically through dimensional analysis. We consider that this equation might be the cause of these discrepancies. Figure 4 shows the spectral features of the shockwave and induced ground motions recorded at GOS2A-P3 and S3. Both the spectrums show a clear harmonic overtone structure and base frequencies of around 7 to $8 \mathrm{~Hz}$. A transfer function is important for understanding air-ground coupling (e.g., Watada, 2009). Following Watada (2009), we define the transfer function as $Z(\omega)=\rho V_{s} v_{z}(\omega) / p(\omega)$, where $\omega$ is the angular frequency, $p$ the pressure perturbation, $\rho$ the density of the elastic media, $V_{s}$ the shear wave velocity of the elastic media, and $v_{z}$ the vertical ground velocity. Since the numerator represents the pressure in the elastic media, the transfer function $Z(\omega)$ is to be nearly unity, because of the stress continuity on the surface. In the case of our reentry observation, $\rho$ and $V_{s}$ values at observation sites are $\sim 1500 \mathrm{~kg} / \mathrm{m}^{3}$ and $\sim 300 \mathrm{~m} / \mathrm{s}$, respectively, which gives a value of $\sim 2$ at a frequency of around $8 \mathrm{~Hz}$. The slight discrepancy is probably due to the applied values of the ground properties. The effective depth of air-to-ground coupling in this frequency range is very shallow and the observation sites are covered with fine soil. Therefore, the applied values may be somewhat overestimated.

For the seismic records at GOS2 and GOS2A, precursor wave packets are clearly identified before the directcoupled wave detection (Fig. 3). Ben-Menahem and Singh (1981) derived a formula for the case of a flat interface between fluid and elastic media. In the case of an acoustic plane wave incident to the interface, the acoustic wave that is converted to a seismic surface wave (Rayleigh wave) is propagated with its phase velocity in the elastic media. If the apparent velocity of the incident acoustic wave is nearly the same as the phase velocity of the seismic surface wave in the elastic media, the seismic surface wave is excited efficiently. Therefore, these wave packets are probably air-coupled seismic surface waves generated slightly away from each seismic sensor. On the other hand, at GOS2B and GOS2B-sub1 to GOS2B-sub3 stations, we did not detect such precursor waves. This is probably due to the apparent velocities of infrasound waves being much higher than the phase velocity of seismic surface waves at these stations, and, consequently, the seismic surface wave could not be 
excited efficiently.

Figure 5 shows the results of an F-K spectrum analysis (MUSIC; e.g., Ueno et al., 2010) and a particle motion of three-component seismograms at GOS2A. For both analyses, we applied a very narrow band pass filter (1-3 $\mathrm{Hz})$ and the analysis time window was $0.5 \mathrm{~s}(13: 55: 31.4$ to 13:55:31.9 UT) in which the main pulse is included. The optimum values of NS and EW slownesses are $-2.13 \mathrm{~s} / \mathrm{km}$ and $-0.32 \mathrm{~s} / \mathrm{km}$, respectively. In other words, the apparent velocity of the wave is $464.3 \mathrm{~m} / \mathrm{s}$, and the azimuth of the wave is $-171.5^{\circ}$ (from magnetic north), the elevation angle of the wave is $42.9^{\circ}$. Those results agree well with the predicted azimuth $\left(-163.6^{\circ}\right.$ from true north, i.e. $\sim-169.5^{\circ}$ from magnetic north) and elevation angle $\left(45.1^{\circ}\right)$ of the sonic boom arrival based on the nominal aerial trajectory of the H-SRC with an isothermally-still atmosphere. Small discrepancies are probably due to winds, a perturbation of sound velocity structures of the atmosphere from the reference (these effects are neglected in calculation), and a measurement error of the magnetic north direction of the array geometry that was measured by a hand bearing compass with an uncertainty of $\sim 2 \circ$. In addition, the threecomponent seismograms of the main pulse at GOS2A station indicate a linear-polarized particle motion along the propagating direction on the horizontal plane and an elliptical particle motion on the vertical plane. These particle motions are typical for Rayleigh wave.

\section{Conclusions}

The Hayabusa, the world's first sample-return (round trip) minor body explorer, returned to the Earth, and reentered the Earth's atmosphere on June 13, 2010. In order to study bolide phenomena, ground-based observations of the reentry were carried out in WPA, Australia, as an extremely rare artificial meteorite fall event. Infrasound/seismic observations were made by deploying a temporal network that consisted of three-arrayed infrasound/seismic and three seismic sub-stations. Clear shockwave records were successfully obtained at all six stations. In particular, we simultaneously obtained shockwave waveforms with positive overpressures of 1.3 Pa, 1.0 Pa, and 0.7 $\mathrm{Pa}$ (corresponding to the H-SRC) and the converted ground-motion waveforms at slant distances of $36.9 \mathrm{~km}, 54.9 \mathrm{~km}$, and $67.8 \mathrm{~km}$, respectively. The incident vectors of the shockwave at each array station were estimated by an F-K spectrum and indicate good agreement with those predicted. Particle motions of the shockwave that converted to ground motions show typical Rayleigh wave characteristics.

Acknowledgments. We thank all members of the Hayabusa Project, especially the sample-return capsule resumption team. Seismometers and loggers were provided from RCEP/DPRI of Kyoto University and RSVD of Nagoya University as a service of equipment sharing. We thank Dr. Takuto Maeda at Earthquake Research Institute of University of Tokyo for providing the array analysis program. We would like to acknowledge the constructive comments of two anonymous referees, which led us to improve the manuscript. We used the Generic Mapping Tools (GMT) software (Wessel and Smith, 1991) for drawing the figures. This research was mainly supported by the Ministry of Education, Science, Sports and Culture, Grant-in-Aid for Scientific Research (B), Field Research in Abroad, 22403005, 2010 (PI: Y.H.).

\section{References}

Ben-Menahem, A. and S. J. Singh, Seismic Waves and Sources, Springer, New York, 1981.

Borovičkia, J., P. Suprný, P. Kalenda, and E. Tagliaferri, The Morávka meteorite fall: 1. Description of the events and determination of the fireball trajectory and orbit from video records, Meteorit. Planet. Sci., 38, 975-987, 2003.

Brown, P., D. O. ReVelle, E. Tagliaferri, and A. R. Hildebrand, An entry model for the Tagish Lake fireball using seismic, satellite and infrasound records, Meteorit. Planet. Sci., 37, 661-675, 2002.

Cevolani, G., The explosion of the bolide over Lugo di Romagna (Italy) on 19 January 1993, Planet. Space Sci., 42, 767-775, 1994.

Edwards, W. N., D. W. Eaton, P. J. McCausland, D. O. ReVelle, and P. G. Brown, Calibrating infrasonic to seismic coupling using the Stardust sample return capsule shockwave: Implications for seismic observations of meteors, J. Geophys. Res., 112, B10306, doi:10.1029/2006JB004621, 2007.

Fujita, K., M.-Y., Yamamoto, S. Abe, Y. Ishihara, O. Iiyama, Y. Kakinami, Y. Hiramatsu, M. Furumoto, H. Takayanagi, T. Suzuki, T. Yanagisawa, M. Shoemaker, M. Ueda, Y. Shiba, and M. Suzuki, An overview of JAXA's ground observation activities for HAYABUSA reentry, Publ. Astron. Soc. Jpn., 63, 961-969, 2011.

Halliday, I., A. A. Griffin, and A. T. Blackwell, The Innisfree Meteorite fall: A photographic analysis of fragmentation, dynamics and luminosity, Meteoritics, 16, 153-170, 1981.

Halliday, I., A. A. Griffin, and A. T. Blackwell, Detailed data for 259 fireballs from the Canadian camera network and inferences concerning the influx of large meteoroids, Meteoriteics, 31, 185-217, 1996.

Ishihara, Y., S. Tsukada, S. Sakai, Y. Hiramatsu, and M. Furumoto, The 1998 Miyako fireball's trajectory determined from shock wave records of a dense seismic array, Earth Planets Space, 55, e9-e12, 2003.

Ishihara, Y., M. Furumoto, S. Sakai, and S. Tsukada, The Kanto large bolide's trajectory determined from shockwaves recorded by a seismic network and images taken by a video camera, Geophys. Res. Lett., 31, L14702, doi:10.1029/2004GL020287, 2004.

Jenniskens, P., P. Wercinski, J. Olejniczak, M. Wright, G. Raiche, D. Kontinos, P. N. Desai, D. Spalding, K. Sandquist, G. Rossano, R. W. Russell, D. O. Revelle, D. Hladiuk, and A. R. Hildebrand, Surface heating from remote sensing of the hypervelocity entry of the NASA GENESIS sample return capsule, 44th AIAA Aerospace Sciences Meeting and Exhibit, Reno Nv. January 9-15, 2006, AIAA-2006-0381 [\#090], 2006.

Kasuga, T., J. Watanabe, and N. Ebizuka, A 2004 Geminid meteor spectrum in the visible-ultraviolet region, Astron. Astrophys., 438, L17-L20, doi:10.1051/0004-6361:200500142, 2005.

McIntosh, B. A., M. D. Watson, and D. O. ReVelle, Infrasound from a radar-observed meteor, Can.J. Phys., 54, 655-662, 1976.

Nagasawa, K., An analysis of sonic boom from a great fireball on May 10, 1977, recorded on seismographs of volcano observations, Bull. Earthq. Res. Inst. Univ. Tokyo, 53, 271-280, 1978 (in Japanese with English abstract).

Pujol, J., P. Rydelek, and Y. Ishihara, Analytical and graphical determination of the trajectory of a fireball using seismic data, Planet. Space Sci., 54, 78-86, 2006.

ReVelle, D. O., On Meteor-Generated Infrasound, J. Geophys. Res., 81 1217-1230, 1976.

ReVelle, D. O., W. N. Edwards, and T. D. Sandoval, Genesis-An artificial, low velocity "meteor" fall and recovery: September 8, 2004, Meteorit. Planet. Sci., 40, 895-916, 2005.

Ueno, T., T. Maeda, K. Obara, Y. Asano, and T. Takeda, Migration of low-frequency tremors revealed from multiple-array analyses in western Shikoku, Japan, J. Geophys. Res., 115, B00A26, doi:10.1029/2008JB006051, 2010.

Watada, S., Radiation of acoustic and gravity waves and propagations of boundary waves in the stratified fluid from a time-varying bottom boundary, J. Fluid Mech., 627, 361-377, 2009.

Wessel, P. and W. H. F. Smith, Free software helps map and display data, Eos Trans. AGU, 72, 441, doi:10.1029/90EO00319, 1991.

Yamamoto, M.-Y., Y. Ishihara, Y. Hiramatsu, K. Kitamura, M. Ueda, Y. Shiba, M. Furumoto, and K. Fujita, Detection of acoustic/infrasonic/seismic waves generated by hypersonic reentry of HAYABUSA capsule and fragmented parts of spacecraft, Publ. Astron. Soc. Jpn., 63, 971-978, 2011.

Y. Ishihara (e-mail: ishihara.yoshiaki@nies.go.jp), Y. Hiramatsu, M. Yamamoto, M. Furumoto, and K. Fujita 